\title{
Maturation of pig oocytes in vivo and in vitro
}

\author{
R. M. Moor*, M. Mattiolif, J. Dingł and T. Nagai§ \\ * Department of Molecular Embryology. Institute of Animal Physiology \& Genetics Research, \\ Babraham. Cambridge CB2 4AT, UK; †Istituto Fisiologia Veterinaria, Bologna, haly: \\ $\ddagger$ Jiangsu Agricultural College, Yangzhou Jiangsu, People's Republic of China; and \\ $\S N a t i o n a l$ Institute of Animal Industry. Tsukuba Norindanchi, Japan
}

Keywords: oocyte; maturation; meiosis; differentiation; fertilization; pig

\section{Introduction}

Germ cells in female embryos enter the germinal ridge, complete a series of mitotic cycles and, in the interphase after the last mitotic division, undergo a final phase of DNA replication (S phase) before entering meiosis. Progression through prophase (G2 stage) is continuous until late diplotene where meiosis is arrested. Development from a non-growing primordial oocyte in meiotic arrest to a transcriptionally active embryo depends upon a series of critical developmental switches. The first of these switches initiates a unique programme of growth which differs from that in somatic cells both because it occurs in the absence of accompanying cell division and because it represents a period of intensive synthesis and storage of macromolecules. During most of its growth the oocyte is incapable of making the transition from prophase (G2) to metaphase ( $M$ phase). The competence to complete this crucial $G 2$ to $M$ phase transition is attained in two phases; the ability to progress from prophase to prometaphase occurs about the time oocyte growth is completed, while progression to MI (the alignment of chromosomes on the first metaphase plate) is delayed until nucleolar transcriptional activity is reduced. Follicle cells provide obligatory metabolic and instructional support to the oocyte throughout the growth phase.

A second developmental switch, activated by the preovulatory LH surge, initiates a phase of intracellular differentiation which confers on the oocyte the ability to support fertilization and early embryonic development. During this phase of maturation changes occur in every intracellular compartment of the oocyte. The association between the follicle cells and oocyte is disrupted, membrane transport increases and a relocation of intracellular organelles occurs. Moreover, some of the mRNA stored during the growth phase becomes translated and the resultant proteins play a critical role in the progression of the meiotic cycle and in regulating sperm penetration and decondensation. Interactions between the follicle cells and oocyte are crucial to the initiation and completion of this phase of differentiation or maturation.

Reorganization and utilization of products sequestered during the first two phases of oocyte growth and differentiation occur in the mitotic cell cycles leading to the third major developmental switch. The consequence of this mid-cleavage transitional switch is to terminate maternal control of development and to activate the embryonic genome. Development after the mid-cleavage transition is directed by new embryonic transcription.

The purpose of this paper is to concentrate on the intracellular changes induced by the first two switches in pig egg development.

\section{Programmed oocyte growth}

The non-growing primordial follicle

About $99 \%$ of the entire stock of female germ cells, estimated in the pig to number approximately 200000 per ovary (Gosden \& Telfer, 1987), remain as non-growing primordial follicles. 
These are embedded in the tunica albuginea and appear to consist of two types with those closest to the germinal epithelium arranged as nests of oocytes with sparse pregranulosa cell investments. Distal to the germinal epithelium primordial follicles occur as discrete units surrounded by a unilaminar layer of somatic. cells (Greenwald \& Moor, 1989). This information is interpreted as suggesting that the change from clustered to isolated oocytes represents a very early event in differentiation and is an essential preparative event for entry into the primary follicle pool.

Because of their relative inaccessibility this important non-dividing population of cells has been poorly studied in any species and virtually not at all in pigs. Virtually nothing is known about the synthetic activity of these cells or about the nature of the switch which converts small numbers of primordial follicles into actively growing primary oocytes. However, with the development of enzymic techniques for the isolation of viable primordial follicles from pig ovaries, new opportunities are now being created for the study of these cells (Greenwald \& Moor, 1989; G. Lazzari \& R. M. Moor, unpublished observations).

Preliminary results indicate that uptake and incorporation of amino acids occur at a low level in isolated primordial follicles but is enhanced 4-fold by the presence of somatic cells associated with the oocyte (G. Lazzari \& R. M. Moor, unpublished observations). There is, as yet, however, no evidence that the translational pattern in non-growing oocytes is affected by the associated follicle cells. The similarities and differences between polypeptide profiles in primordial oocytes and fully grown germinal vesicle oocytes can be seen by comparing the fluorograms presented in Figs 1 and 3. As expected, in both developmental states some of the same structural proteins such as actin and tubulin are synthesized. However, specific proteins associated with primordial oocytes exist and justify special study.

The non-growing but metabolically active primordial oocyte responds to the intraovarian growth signal by entering an extremely active synthetic phase. The growth phase is unique and differs from somatic cells in three important respects. Firstly, although the oocyte increases in volume approximately 200 -fold during growth, the entire process occurs in the complete absence of cell division. Secondly, many of the products of transcription and translation are not utilized during this phase of active growth but are stored instead for utilization in early embryogenesis. Thirdly, a complex series of continuously changing interactions with the surrounding somatic elements regulates both growth and cell cycle function in these oocytes. During the primordial stages follicle cells surrounding the oocyte probably exert inhibitory influences on germ cell growth. According to Thibault et al. (1987) the inhibitory role of the follicle cells disappears when these cells are stimulated by unknown mechanisms to enter mitosis. Thereafter, somatic support, mediated via intercellular coupling, is crucial for oocyte growth. Results from studies in mice show that while metabolic co-operation with somatic cells is essential, it is not itself adequate for oocyte growth (Eppig, 1977, 1979; Bachvarova et al., 1980; Herlands \& Schultz, 1984). Indeed, recent co-culture experiments suggest that mitotically activated follicle cells provide specific but undefined oocyte growth supporting substances not provided by other cells types (Buccione et al., 1987). At an advanced stage in the growth phase the follicle cells again become inhibitory but at this time their action is directed towards blocking the meiotic cycle in the oocyte at prophase. A final reversal to a facilitatory role occurs just before ovulation when the follicle cells stimulate maturational changes within the oocyte.

The growth phase in pig oocytes extends throughout the preantral follicle stage and is not completed until the antral follicle has reached a diameter of about $2.2 \mathrm{~mm}$ (Motlik et al., 1984a). Autoradiographic and cytochemical analyses show that pig oocytes are intensely engaged in both ribosomal (rRNA) and heterogeneous (hnRNA) RNA synthesis until a late stage in growth (Motlik et al., 1984b). Nucleolar compaction, the accompanying cessation of RNA synthesis and the capacity to progress from the germinal vesicle (GV) to the MII phase of meiosis all occur when the pig oocyte approaches its full size in the antral follicle (Table 1). Over $80 \%$ of oocytes of $100 \mu \mathrm{m}$ diameter $(80 \%$ of full size) remain blocked at the GV phase after $24 \mathrm{~h}$ in culture whereas all fully grown oocytes have undergone germinal vesicle breakdown (GVBD) during the same period in 


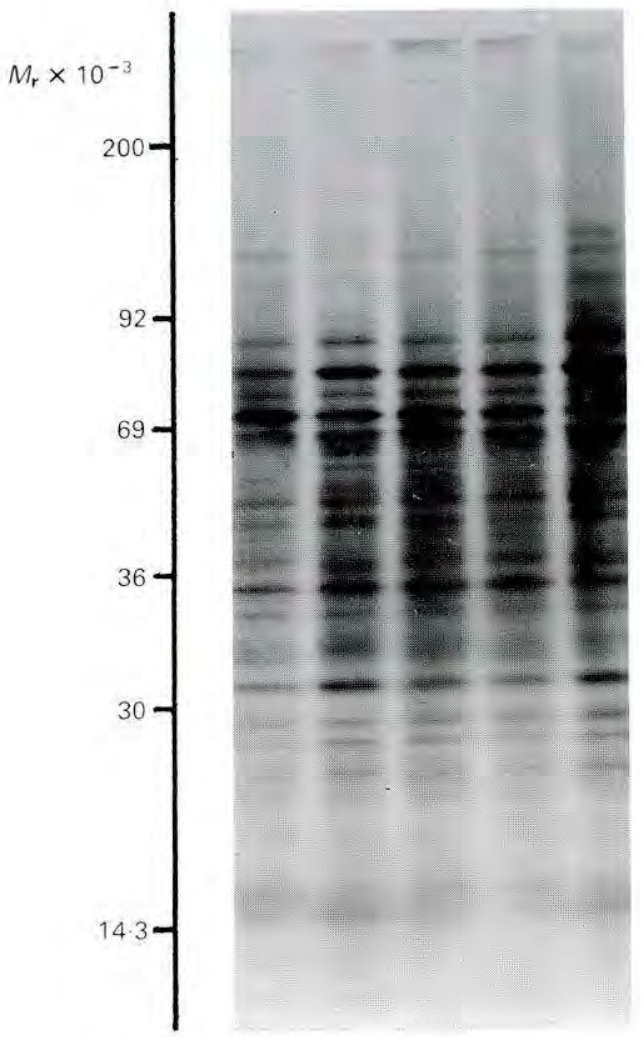

Fig. 1. Fluorogram of $\left[{ }^{35}\right.$ S $]$ methionine-labelled polypeptides from pig primordial oocytes. Primordial follicles were isolated from the ovaries of piglets by enzymic digestion, labelled for $18 \mathrm{~h}$ before the oocytes were separated from their follicle cells and run on $8-15 \%$ SDS polyacrylamide gradient gels (G. Lazzari \& R. M. Moor, unpublished observations).

vitro (Motlík et al., 1984a). Approximately half the growing oocytes (100 $\mu \mathrm{m}$ diameter) undergo delayed GVBD in the next $24 \mathrm{~h}$ but none of these progresses beyond MI. The acquisition of meiotic competence in pigs appears, therefore, to be developed in stages starting with a limited and delayed capacity to undergo the $\mathrm{G} 2$ to prometaphase transition as full size is approached. The ability to complete the MI to MII transition coincides with the cessation of nucleolar transcriptional activity, the growth to full size and the capacity to synthesize the complete range of metaphase-stage proteins (McGaughey et al., 1979).

Table 1. Relationship between oocyte size, RNA synthesis and the capacity to undergo meiotic maturation during a 24-h culture period in vitro (after Motlík et al., 1984a; Motlík \& Fulka, 1986)

\begin{tabular}{|c|c|c|c|c|c|c|}
\hline \multirow{3}{*}{$\begin{array}{l}\text { Oocyte } \\
\text { diameter } \\
(\mu \mathrm{m})\end{array}$} & \multirow{3}{*}{$\begin{array}{l}\text { Nucleolar } \\
\text { morphology }\end{array}$} & \multirow{2}{*}{\multicolumn{2}{|c|}{ Uridine incorporation }} & \multicolumn{3}{|c|}{ Meiotic status ( $\%$ oocytes) } \\
\hline & & & & \multirow[b]{2}{*}{ GV } & \multirow{2}{*}{$\begin{array}{l}\text { Chromatin } \\
\text { condensation }\end{array}$} & \multirow{2}{*}{$\begin{array}{l}\text { Metaphase } \\
\text { plates }\end{array}$} \\
\hline & & Nucleoplasm & Nucleolus & & & \\
\hline 100 & Fibrillo-granular & +++ & $++t$ & 85 & 12 & 0 \\
\hline 115 & Partial compaction & +++ & ++ & 6 & 46 & 49 \\
\hline 120 & Compact & + & - & 0 & 43 & 56 \\
\hline
\end{tabular}


The intracellular events associated with the acquisition of meiotic competence have been examined in a series of novel cell-fusion studies (see Motlík \& Fulka, 1986). Growing pig oocytes were isolated from small antral follicles $(0.5 \mathrm{~mm}$ diameter $)$ and fused with fully grown oocytes at different stages of the meiotic cycle. The results summarized in Table 2 show firstly that nuclei in growing oocytes have the capacity to undergo GVBD and form metaphase plates when exposed to appropriate cytoplasmic signals from fully grown metaphase-staged oocytes. By contrast growing oocytes fused with fully grown GV oocytes inhibit GVBD in both fusion partners (Motlík \& Fulka, 1986). This inhibitory action of the immature cytoplasm is not species specific and blocks GVBD in a time-dependent manner. These results are interpreted as showing that an essential cell cycle component, Maturation Promoting Factor (MPF; Masui \& Markert, 1971) is produced by fully grown oocytes between 8 and $12 \mathrm{~h}$ after the induction of maturation. If sufficient amounts of MPF are present at fusion then both sets of chromosomes undergo condensation. However, fusion in the first 6-8 h blocks MPF synthesis and both the growing and fully grown oocytes remain in the G2 phase of meiosis (Motlik \& Fulka, 1986). While it is still premature to conclude that the missing factor in immature oocytes is MPF, nevertheless it is apparent that proteins necessary for cell cycle progression are absent or limiting in growing oocytes. After completion of the growth phase the oocyte first becomes capable of undergoing the series of differentiation events which prepare it for fertilization and development.

Table 2. Effect on nuclear development of fusing growing ( $100 \mu \mathrm{m}$ diameter) and fully grown oocytes $(120 \mu \mathrm{m})$ at different stages of meiosis (after Fulka et al., 1985)

\begin{tabular}{ccccccc}
\hline \multicolumn{2}{c}{$\begin{array}{c}\text { Oocyte } \\
\text { combination }\end{array}$} & & Prefusion & & \multicolumn{2}{c}{$\begin{array}{c}\% \text { of oocytes after } \\
\text { culture with: }\end{array}$} \\
\cline { 1 - 1 } $\begin{array}{c}\text { Cell 1 } \\
(\mu \mathrm{m})\end{array}$ & $\begin{array}{c}\text { Cell 2 } \\
(\mu \mathrm{m})\end{array}$ & $\begin{array}{c}\text { Post-fusion } \\
\text { culture period } \\
\text { of Cell 1 }(\mathrm{h})\end{array}$ & $\begin{array}{c}\text { culture } \\
(\mathrm{h})\end{array}$ & $\begin{array}{c}\text { No. of } \\
\text { fused } \\
\text { oocytes }\end{array}$ & $\begin{array}{c}2 \text { dictyate } \\
\text { nuclei }\end{array}$ & $\begin{array}{c}2 \text { metaphase } \\
\text { nuclei }\end{array}$ \\
\hline 120 & 120 & 0 & 30 & 80 & 6 & 94 \\
120 & 100 & 0 & 30 & 120 & 92 & 8 \\
120 & 100 & 6 & 24 & 41 & 98 & 2 \\
120 & 100 & 12 & 18 & 45 & 51 & 49 \\
120 & 100 & 24 & 3 & 36 & 6 & 94 \\
\hline
\end{tabular}

\section{Dictyate arrest in fully grown oocytes}

The signals responsible for the maintenance of meiotic arrest in fully grown oocytes are unclear but are known to be of granulosa cell origin (Foote \& Thibault, 1969). It is further accepted by most, but not all, investigators that signals generated by the follicle cells are dependent for their action on functional intercellular coupling between the somatic and germ-cell compartments (Dekel \& Beers, 1978; Meinecke \& Meinecke-Tillman, 1981). Since almost all the experiments on meiotic arrest in pig oocytes have been carried out in vitro it is salutory to examine firstly the spontaneous changes that occur in the signal-generating cells and in intercellular coupling between the oocyte and follicle cells in culture. An appreciation of the potential problems associated with invitro culture systems is important when considering the large amount of conflicting evidence on meiotic inhibitors in pigs (see Thibault et al., 1987). That the granulosa compartment alters rapidly and extensively when its morphological integrity is disrupted is clear both with respect to steroidogenesis and protein synthesis and secretion (see Moor \& Seamark, 1986; Moor \& Crosby, 1987). There is therefore a high probability that intrafollicular signals may be altered or lost in extrafollicular culture systems. Motlík et al. (1986) report that intercellular coupling in pig oocytes is prematurely disrupted in vitro, especially if appropriate gonadotrophins are not present in the culture medium. These authors showed that intercellular communication between the somatic and 
germinal compartment in vivo is high in GV oocytes and only decreases about $32 \mathrm{~h}$ after hCG at anaphase I or telophase I. By contrast, uncoupling occurs progressively and is almost complete as early at $16 \mathrm{~h}$ after explanation in oocyte-cumulus complexes obtained from prepubertal gilts and cultured in the absence of gonadotrophins; the administration of PMSG to pigs before slaughter or the addition of FSH to the culture medium after explantation reduces the rate of uncoupling observed in vitro (Motlík et al., 1986). However, intercellular coupling equivalent to that observed in vivo has been obtained in pig oocyte complexes (Fig. 2) only after co-culture with segments of extroverted follicle or with medium preconditioned by extroverted follicles (Mattioli et al., 1988b). Experiments designed to identify the component required for the maintenance of junctional integrity show that an ether extract of preconditioned medium or progesterone alone effectively maintains intercellular coupling whilst androgens and oestradiol-17 $\beta$ are totally ineffective in this respect (Mattioli et al., 1988b). These studies suggest that an important action of the follicle cells is to maintain a high degree of intercellular coupling until a late stage of maturation in pig oocytes. A re-examination of published work shows that the requirements for normal junctional function have seldom been provided in experiments on dictyate arrest in full-grown pig oocytes in vitro. Add to this the probable changes in granulosa cell signals in culture and the difficulties in interpreting the large amount of conflicting evidence on the meiotic block in pigs becomes apparent. For example, there are papers which claim, and other which dispute, that cyclic AMP, small peptides (OMI: oocyte maturation inhibitor), steroids, purines and many other factors act as meiotic inhibitors (for references see Racowsky, 1985; Thibault et al., 1987). A careful analysis by Thibault et al. (1987) integrates the disparate reports on the meiotic block and favours a multiple control system involving cAMP, OMI and other factors. Our approach is to concentrate on the events that occur before and during the $\mathrm{G} 2$ to $\mathrm{M}$ phase transition; it is anticipated that the nature of the meiotic inhibitors will become more apparent when the intracellular mechanisms involved in GVBD are more fully understood.

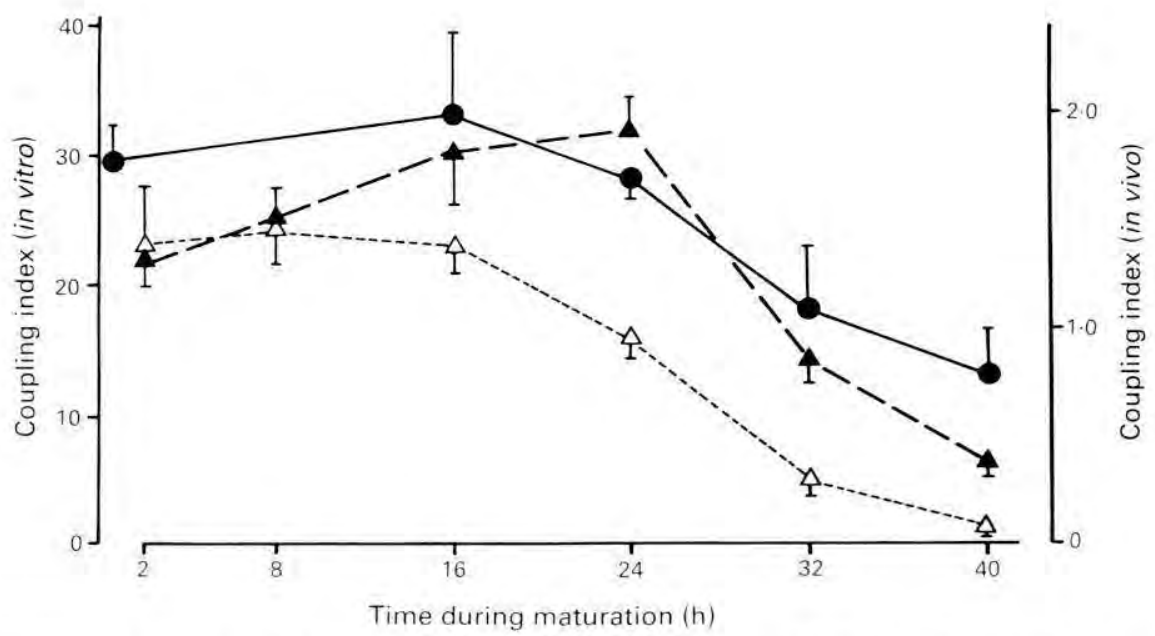

Fig. 2. Degree of intercellular coupling between the oocyte and follicle cells at different stages of maturation in vivo and in vitro. The intercellular coupling index and s.e.m. (A-B/B where $A=$ uptake of $\left[{ }^{3} \mathrm{H}\right]$ uridine by cumulus enclosed oocyte and $\mathrm{B}=$ uptake in denuded oocytes) was calculated for oocytes removed directly from the ovaries 1986) or after culture in control $(\triangle---\triangle)$ or follicle-cell conditioned medium $(\boldsymbol{\Delta}---\boldsymbol{\Delta})$ in vitro (Mattioli et al., 1988b). 


\section{The maturation programme}

\section{Induction of maturation}

Irrespective of the nature of the intrafollicular meiotic inhibitor there is little doubt that its effect is reversed in vivo by the high levels of gonadotrophins (and in particular LH) released before ovulation (see Thibault, 1977). A similar dependence on gonadotrophic support characterizes the maturation of pig oocytes matured in vitro both within intact follicles (Meinecke \& MeineckeTillman, 1981; Fleming et al., 1985) or as cumulus-oocyte complexes with and without further somatic support. Thus, in a stationary culture system only $39 \%$ of oocytes with a small associated cumulus complex $\left(3.5 \times 10^{3}\right.$ cells $)$ reached metaphase II after $44 \mathrm{~h}$ in culture with appropriate gonadotrophins as compared with $87 \%$ of oocytes surrounded by a large $\left(150 \times 10^{3}\right)$ cumulus complex (T. Nagai, J. Ding \& R. M. Moor, unpublished observations). After exposure to elevated gonadotrophin concentrations changes occur both to the structure and function of the somatic cell compartment (Thibault, 1977; Ainsworth et al., 1980) and to the oocyte. The strong presumption is that the functional changes in the follicle cells act both to suppress the somatic cell-derived meiotic inhibitors and to facilitate directly differentiation events in the oocyte which underly normal fertilization and early embryogenesis (see Thibault et al., 1987; Mattioli, 1989, for references).

\section{Cytoplasmic differentiation}

The re-organization and utilization of products sequestered during oocyte growth constitute a major component of the maturation programme. These differentiation events are not dependent upon nuclear regulation but instead control both the progression of the meiotic cycle and the other intracellular events that confer developmental competence on the fully grown oocyte. The changes involve all the major structural and functional components in the oocyte and are facilitated or directly regulated by the somatic cells in the follicle.

Pig oocytes retain functional intercellular communication with adjacent follicle cells for a longer period during maturation than any other species. The data presented in Fig. 2 show that the coupling index is as high in oocytes at MI as it is in GV oocytes; significant uncoupling is not observed until about $32 \mathrm{~h}$ after the induction of maturation. To compensate for this loss of an uptake system, junctional uncoupling is accompanied by an increase in membrane transport in sheep oocytes (Moor, 1983). Although no comparable measurements on membrane transport have yet been made on pig oocytes, new data obtained by one of us (M.M.) show that the membrane potential of the pig oolemma is twice as high in cumulus-enclosed oocytes $(45 \mathrm{mV})$ as it is in denuded oocytes $(28 \mathrm{mV})$.

The relocation of organelles within the oocyte during maturation involves both mitochondria and cortical granules. Mitochondria, which are uniformly distributed throughout the cytoplasm in GV oocytes, become aggregated around the nucleus at the time of its breakdown during maturation (Thibault et al., 1987). This mitochondrial clustering and subsequent dispersal at anaphase/ telophase is both microtubule-dependent and necessary for the progression of maturation.

It is noteworthy that the oocyte-specific mitochondria persist after fertilization whilst the mitochondria of paternal origin degenerate. Zygote mitochondria are therefore of maternal origin only.

While the mitochondria migrate to occupy a peri-nuclear position during maturation, the cortical granules migrate outward to form an irregular monolayer a few nanometres beneath the cell membrane by the time maturation is complete (Cran \& Cheng, 1986). A cytoplasmic zone devoid of organelles often forms beneath the monolayer of cortical granules whilst a fine actin filament layer is interposed between the cortical granules and oolemma. It is apparent that the migration of cortical granules is an essential prelude to the formation of the block to polyspermy. The development of the fine actin filament layer is most probably involved in the stabilization of the cortical 
granules immediately beneath the oolemma and these filaments may, in addition, be important for exocytosis. It is as yet unclear why a zone lacking organelles forms beneath the cortical granules in pig oocytes, especially since it might be anticipated that storage of $\mathrm{Ca}^{2+}$ adjacent to the cortical granules is required for exocytosis.

The cytological remodelling is accompanied by a major reprogramming of protein synthesis involving the utilization of approximately $30 \%$ of the polyadenylated RNA stored during oocyte growth (Bachvarova et al., 1985). The extent of protein reprogramming in pig oocytes is illustrated in Fig. 3; that this reprogramming involves both the initiation of new synthesis and also the cessation of synthesis of certain GV-stage proteins is apparent from the fluorograms. Results for sheep, not yet repeated using pig oocytes, show that the polysomal capacity during maturation is limiting, thus necessitating a balance between termination of certain proteins and initiation of new protein synthesis (Moor \& Powell, 1989). The crucial role of newly synthesized proteins in, for example, driving the meiotic cycle to completion and in inducing male pronuclear formation after maturation provide important examples of the developmental significance of intra-oocyte reprogramming and the role of new protein synthesis before ovulation.

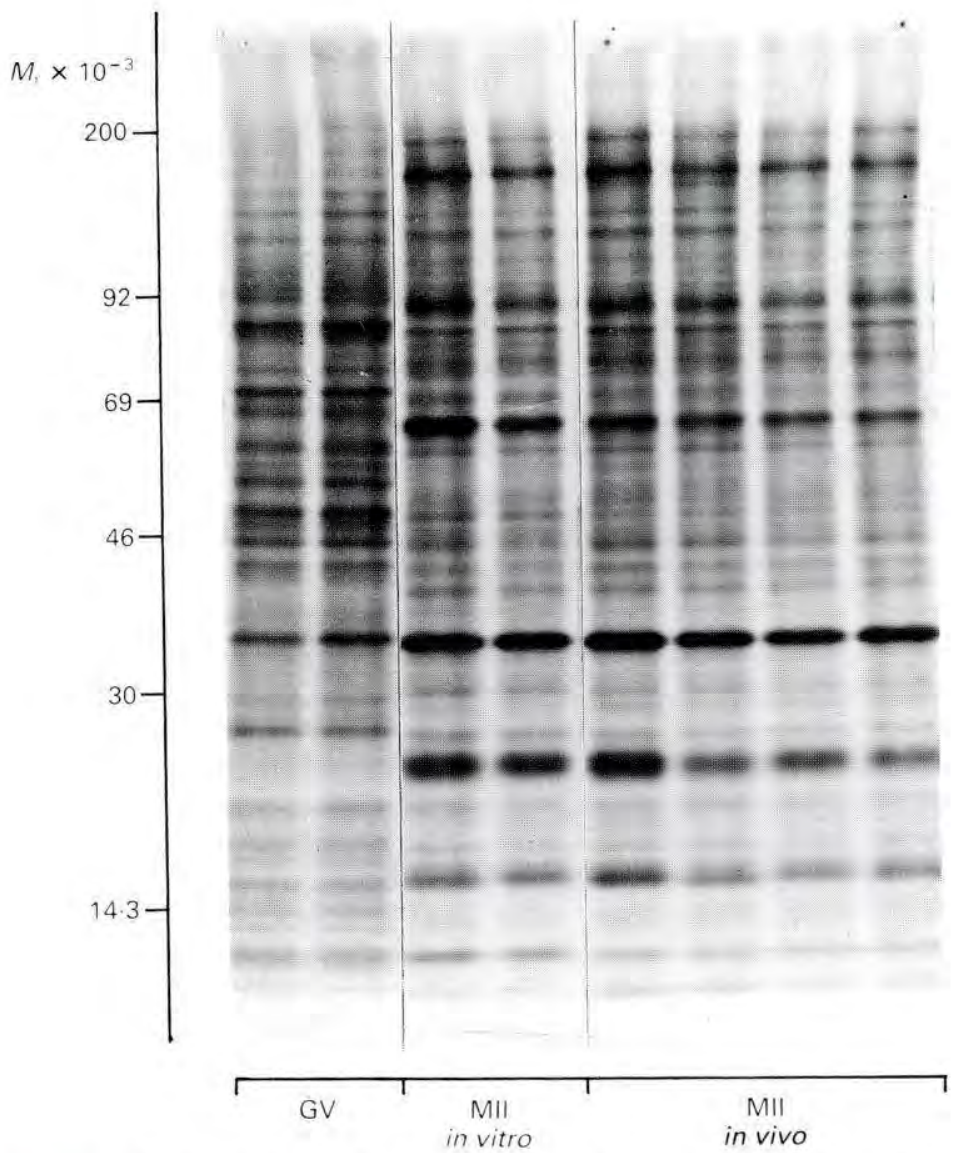

Fig. 3. Fluorogram of ${ }^{35} \mathrm{~S}$-labelled polypeptides from pig oocytes at the germinal vesicle stage and after maturation for $44 \mathrm{~h}$ in vitro or in vivo. Oocyte-cumulus complexes were radiolabelled for $3 \mathrm{~h}$ and then the oocytes were denuded of follicle cells and run on an 8-15\% SDS polyacrylamide gradient gels (R. M. Moor, unpublished observations). 


\section{Meiotic progression during maturation}

A detailed cytological analysis of the meiotic events during maturation shows that the initial chromatin changes occur in the follicular phase before the LH surge (Daguet, 1980). During this initial phase (GV0) the dispersed chromatin, characteristic of oocytes in the luteal phase, undergoes partial condensation with chromatin aggregations around the nucleolus and in irregular clusters against the nuclear membrane (GV1). According to Motlík \& Fulka (1976) the ensuing interval from the release of $\mathrm{LH}$ to the breakdown of the nuclear membrane takes $20-24 \mathrm{~h}$ and can be divided into four distinct phases. About 8-10 h after exposure to $\mathrm{LH}$ a few chromocentres form on the nuclear membrane (GV2) and by $16 \mathrm{~h}$ most oocytes exhibit chromatin clumping and the beginning of strand formation (GV3). In the final phase, terminating at 20-24 h after LH, disappearance of the nucleolus, condensation of the chromatin to form an irregular network or individual bivalents and the breakdown of the nuclear membrane occurs. The ultrastructural features of these processes have been outlined by Thibault et al. (1987). These combined results indicate that the progression from the $\mathrm{G} 2$ to $\mathrm{M}$ phase of the meiotic cycle consists of a series of temporally unrelated events involving, firstly, chromatin condensation, then nucleolar dissolution and finally nuclear membrane breakdown. We postulate that different mechanisms probably control each of the major events in the $\mathrm{G} 2$ to $\mathrm{M}$ phase transition, thus imposing a multi-regulatory system on this critical developmental switch.

\section{Regulation of the $\mathbf{G 2}$ to $\mathrm{M}$ phase transition}

Pig oocytes, in common with those of the sheep and cow, have an absolute requirement for protein synthesis in the period immediately before GVBD for the normal progression of the meiotic cycle (Fulka et al., 1986b; Moor \& Crosby, 1986; Hunter \& Moor, 1987). The inhibition of protein synthesis at different stages after the induction of maturation in pig oocytes shows that proteins vital for cell cycle progression are synthesized in sufficient amounts for the occurrence of GVBD $12-16 \mathrm{~h}$ after $\mathrm{LH}$. However, new protein synthesis is not required for chromatin condensation or the disappearance of the nucleolus but is absolutely essential for nuclear membrane breakdown (Kubelka et al., 1988). Table 3 illustrates a number of additional important features of the G2 to M transition in pigs. The first is that the inhibitor effect of blocking protein synthesis on GVBD is fully reversible and, more remarkably, breakdown of the nuclear membrane occurs within $4 \mathrm{~h}$ of the removal of the inhibitor. This $4 \mathrm{~h}$ period can be separated into an obligatory $1 \cdot 5-2 \cdot 5 \mathrm{~h}$ period of protein synthesis followed by a further $2 \mathrm{~h}$ before the occurrence of membrane breakdown when further protein synthesis is not required. Moreover, breakdown of the nuclear membrane and chromatin condensation are prevented by the inhibition of proteolysis using an inhibitor of trypsinsensitive proteases ( $p$-aminobenzamidine). After using inhibitors of protein synthesis and proteolysis in a variety of combinations, Kubelka et al. (1988) concluded that protein synthesis and proteolysis are two essential and successive steps in the induction of nuclear membrane breakdown.

Cell fusion studies have been used to investigate further the relationship between the nucleus and cytoplasm in the period before GVBD (Motlik \& Fulka, 1986; Fulka et al., 1986a, 1988; Kubelka et al., 1988). The results suggest that crucial MPF-like factors reach threshold levels in oocytes at $8-16 \mathrm{~h}$ after the induction of maturation. These factors require protein synthesis for their activation or accumulation and are not capable of undergoing autocatalytic amplification as occurs in Xenopus laevis oocytes. It appears that the chromosome condensation activity in pig oocytes is possibly located in the nucleoplasm and is not released into the ooplasm until after nuclear membrane breakdown. With the recent rapid advances in understanding of the eukaryotic cell cycle it is appropriate to attempt a synthesis of the various observations on the G2 to M phase transition in pig oocytes.

It is now clear that the entry of cells into the $\mathrm{M}$ phase is induced by maturation promoting factor (MPF: Masui \& Markert, 1971). The abundance of MPF does not alter during the cell cycle although changes in its state of activation occur especially as the cell enters mitosis. The core 
Table 3. Time-dependent effect of cycloheximide and $p$-aminobenzamidine on chromatin condensation and nuclear membrane breakdown in pig oocytes (after Kubelka et al., 1988)

\begin{tabular}{lcccc}
\hline $\begin{array}{l}\text { lst culture period } \\
(20 \mathrm{~h}) \text { in presence of: }\end{array}$ & $\begin{array}{c}\text { 2nd culture period } \\
\text { without inhibitor } \\
(\mathrm{h})\end{array}$ & $\begin{array}{c}\text { 3rd culture period } \\
\text { with cycloheximide } \\
(\mathrm{h})\end{array}$ & $\begin{array}{c}\text { Chromatin } \\
\text { condensation }\end{array}$ & $\begin{array}{c}\text { Nuclear } \\
\text { membrane } \\
\text { breakdown }\end{array}$ \\
\hline Cycloheximide & 2 & 0 & + & 0 \\
$(10 \mu \mathrm{g} / \mathrm{ml})$ & 4 & 0 & + & 86 \\
& 6 & 0 & + & 100 \\
$p-$ Aminobenzyamidine & 0 & 0 & + & 0 \\
$(1 \mathrm{mM})$ & 6 & 0 & + & 3 \\
& 10 & 5 & + & 28 \\
Cycloheximide & 1 & 4.5 & + & 53 \\
$(10 \mu \mathrm{g} / \mathrm{ml})$ & 1.5 & 3.5 & & 95 \\
& 2.5 & & + & \\
\hline
\end{tabular}

polypeptide in MPF is a phosphoprotein of $M_{\mathrm{r}} 34000$, probably a histone $\mathrm{H} 1$ kinase, with close homology to the yeast cdc2 mitotic regulator (see Lee \& Nurse, 1987; Dunphy \& Newport, 1988; Lokha, 1989). Conversion of the latent $M_{\mathrm{r}} 34000$ phosphoprotein into active MPF appears to involve both dephosphorylation and the formation of complexes between it and a family of cellcycle oscillatory proteins called cyclins (Dunphy \& Newport, 1988; Draetta et al., 1989). Cyclin proteolysis at the metaphase/anaphase transition probably inactivates MPF and allows escape from the $\mathrm{M}$ phase.

We postulate that cyclin-like molecules are synthesized by pig oocytes between 8 and $16 \mathrm{~h}$ after the induction of maturation. These molecules, complexed with dephosphorylated core cdc2 polypeptides of $M_{\mathrm{r}} 34000$, form active MPF which drives the oocyte into metaphase (Fig. 4). It appears possible that partly activated MPF complexes are capable of inducing chromatin condensation whilst high levels of the fully activated complexes are necessary for nuclear membrane breakdown. The apparent requirement for proteolysis before entry into metaphase by the pig oocyte cannot be accounted for by our tentative model and will require further investigation. It is also unclear as to whether meiotic incompetence in growing oocytes reflects a lack of core cdc2 phosphoprotein of $M_{\mathrm{r}} 34000$, an inability to synthesize cyclin or a failure to carry out appropriate post-translational modifications during the formation of the complexes. Finally, we believe that an appreciation of the molecular event underlying the $\mathrm{G} 2$ to $\mathrm{M}$ phase transition will provide a firm basis for the identification of the follicle cell-derived meiotic inhibitors.

\section{Formation of the male pronucleus}

The penetration of spermatozoa in vivo into pig eggs obtained after hGC injection occurs by $3 \mathrm{~h}$ after mating and the synchronous development of the male and female pronuclei is completed about 5-6 h thereafter (Hunter, 1972). Studies on the formation of the male pronucleus have shown that the normal occurrence of this process is entirely dependent upon factors (male pronucleus growth factor: MPGF) present in the fully matured oocyte (Iwamatsu \& Chang, 1972; Thibault et al., 1975). That there is a particularly close relationship between oocyte maturation and male pronucleus formation in pigs has been repeatedly demonstrated and is now being used as a physiological measure of cytoplasmic maturation (see Mattioli et al., 1988a, for references). Incomplete maturation or inadequate conditions in vitro result in partial and/or delayed decondensation. Examples of normal and aberrant forms of decondensation are illustrated in Fig. 5. In the normal sequence of events in pig fertilization, detachment of the sperm head and early swelling occur at about $4 \mathrm{~h}$ after insemination in vitro and is synchronous with the beginning of the second meiotic division (anaphase II) in the egg. At $6 \mathrm{~h}$ after insemination incipient nuclear membranes appear 


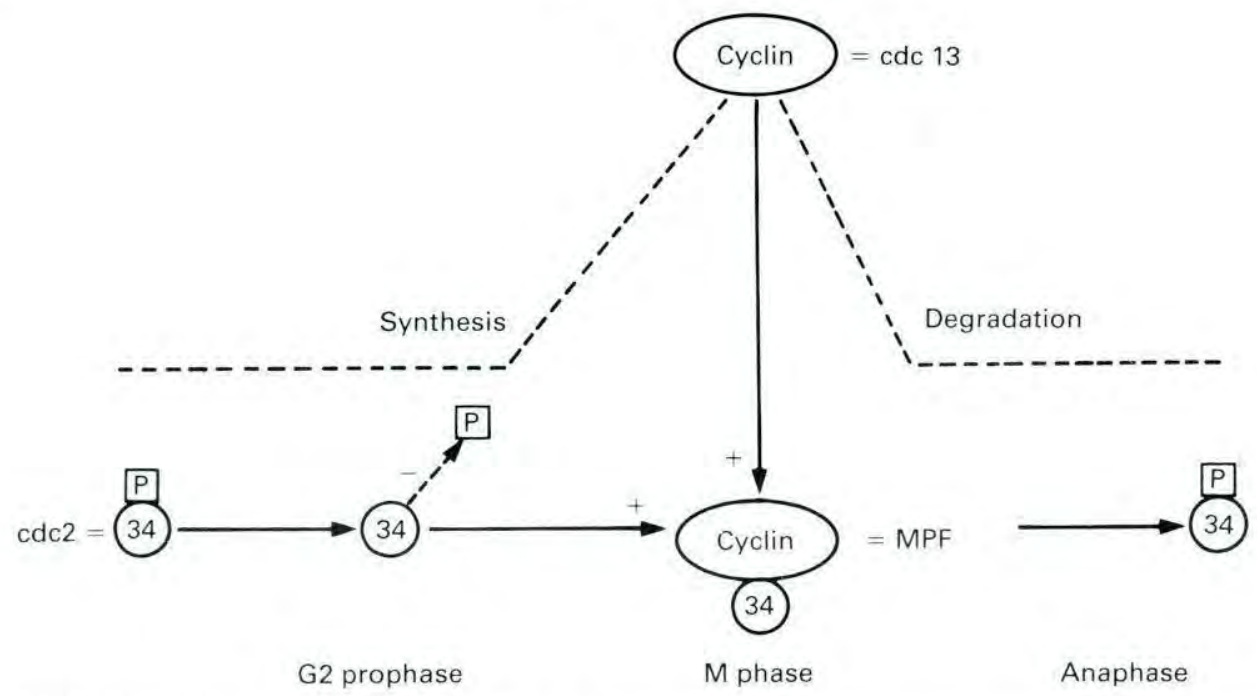

Fig. 4. A model system for the regulation of the $G 2$ to metaphase transition in pig oocytes. During prophase the cde2 protein of $M_{\mathrm{r}} 34000$ is inactive due to post-translational modifications. The activation of the cdc 2 protein and its complexing with cyclin protein results in the production of active maturation promoting factor (modified from Dunphy \& Newport, 1988).

around the decondensed sperm nucleus and around the female chromosomes, and by $7 \mathrm{~h}$ well formed male and female pronuclei are observed.

\section{Regulation of male pronucleus formation}

Our results (Fig. 6) and those of others indicate clearly that pig oocytes matured in vitro in the absence of follicle cells or in the presence of cumulus alone fail to induce normal male pronuclear development (Irritani et al., 1978; Mattioli et al., 1988a). It is evident from recent experiments that oocytes enclosed by $2-4 \times 10^{3}$ cumulus cells undergo inadequate cytoplasmic maturation and fail to induce full condensation. The presence of $15 \times 10^{3}$ follicle cells in the cumulus-oocyte complex or the addition of follicle shells to cultures of cumulus-enclosed oocytes confers normal condensation competence on the eggs (Fig. 6). However, the critical contribution made by the follicle cells to cytoplasmic maturation in pig oocytes is fully evident only when gonadotrophic hormones are present in the medium and when a non-static culture system is used (T. Nagai, J. Ding \& R. M. Moor, unpublished observations).

The observation (Table 4) that the beneficial effect of follicular tissue on decondensation is both cell-specific and can, moreover, be conferred upon cumulus-enclosed oocytes through the use of conditioned medium has been the basis for more detailed investigations of somatic-oocyte signalling during maturation (Mattioli et al., 1988b). It has been established, firstly, that the active decondensation factor in conditioned medium is ether soluble and its effects can be mimicked by the addition of progesterone but not by oestrogens or androgens (Mattioli et al., 1988b). Secondly, it is clear from oocyte denudation studies that the required follicle cell stimulation is necessary for at least the first $32 \mathrm{~h}$ of maturation. The third important observation made by Mattioli et al. (1988b) relates to the role of the follicle cells in maintaining functional intercellular coupling between the oocyte and the follicular compartment. The results show that conditioned medium, ether extracts and progesterone maintain intercellular communication (Fig. 7) and in this manner probably ensure full cytoplasmic differentiation during oocyte maturation. The nature of the molecules directly responsible for decondensation remains unresolved but is the focus of present research. 

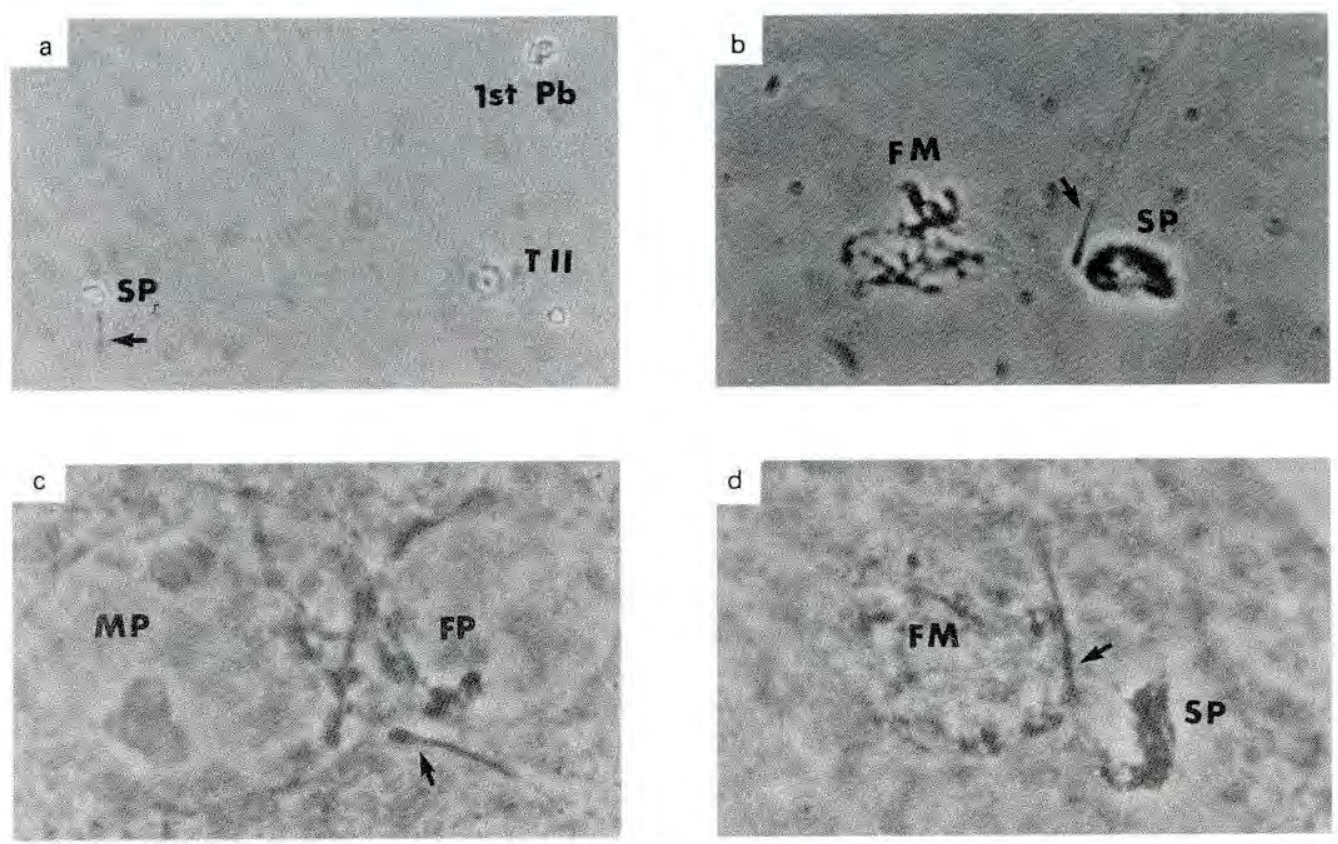

Fig. 5. Phase-contrast photomicrographs of oocytes prepared as whole mounts and stained with $1 \%$ lacmoid. $\mathrm{SP}=$ spermatozoa; 1 st $\mathrm{PB}=$ first polar body; $\mathrm{T} \mathrm{II}=$ telophase II. (a) Slightly swollen sperm head with associated sperm tail (arrow) at $4-5 \mathrm{~h}$ after insemination. The oocyte has progressed through the second meiotic division to telophase II. $\times 500$. (b) At 5-6 h further decondensation of the spermatozoon occurs together with the completion of the second meiotic division and the formation of an incipient nuclear membrane around the oocyte chromatin $(\mathrm{FM}) . \times 1000$. (c) Fully formed male and female pronuclei are observed between 7 and $10 \mathrm{~h}$ after insemination. $\times 1000$. (d) Incomplete maturation results in the asynchronous development of pronuclei. The progression of the chromatin change (FM) in the oocyte and the delayed formation of the male pronucleus is illustrated. $\times 1000$.

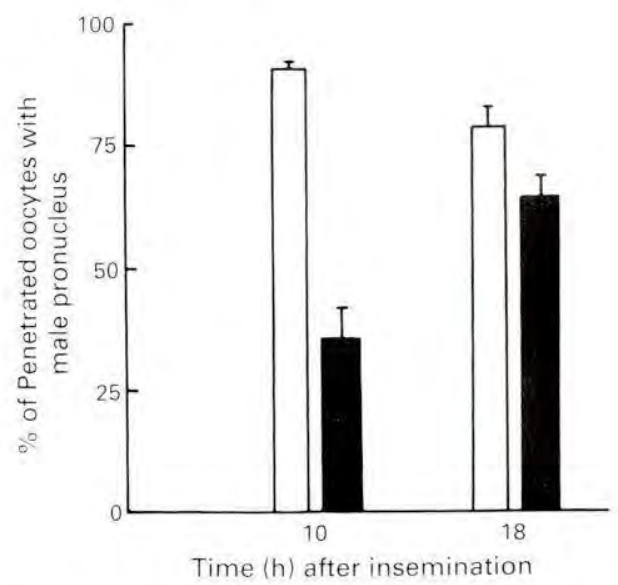

Fig. 6. Effect of the presence $(\square)$ or absence ( $)$ of follicle shell (theca plus granulosa compartments) supplementation on the percentage ( \pm s.e.m., $n=>40$ for each group) and time of male pronucleus formation in pig oocyte-follicle cell complexes $\left(15 \times 10^{3}\right.$ cells $)$, matured and fertilized in vitro (J. Ding, T. Nagai \& R. M. Moor, unpublished observations). 
Table 4. Effect on sperm decondensation of maturing oocytes with different steroid supplementation (after Mattioli et al., 1988b)

\begin{tabular}{lcc}
\hline Supplementation & $\begin{array}{c}\text { No. of } \\
\text { penetrated } \\
\text { oocytes }\end{array}$ & $\begin{array}{c}\text { Oocytes with } \\
\text { decondensed } \\
\text { spermatozoa } \\
(\%)\end{array}$ \\
\hline $\begin{array}{l}\text { None (control medium) } \\
\text { Follicle conditioned } \\
\text { medium }\end{array}$ & 71 & 4 \\
$\begin{array}{l}\text { Ether extract of follicle- } \\
\quad \text { conditioned medium }\end{array}$ & 155 & 80 \\
$\begin{array}{l}\text { Oestradiol-17 } 17 \mu \mathrm{g} / \mathrm{ml}) \\
\text { Androgen } 1(1 \mu \mathrm{g} / \mathrm{ml})^{*}\end{array}$ & 20 & 48 \\
Progesterone $(1 \mu \mathrm{g} / \mathrm{ml})$ & 63 & 1 \\
\hline
\end{tabular}

*Androstenedione, testosterone and dihydrotestosterone considered together because of similar action on fertilization.

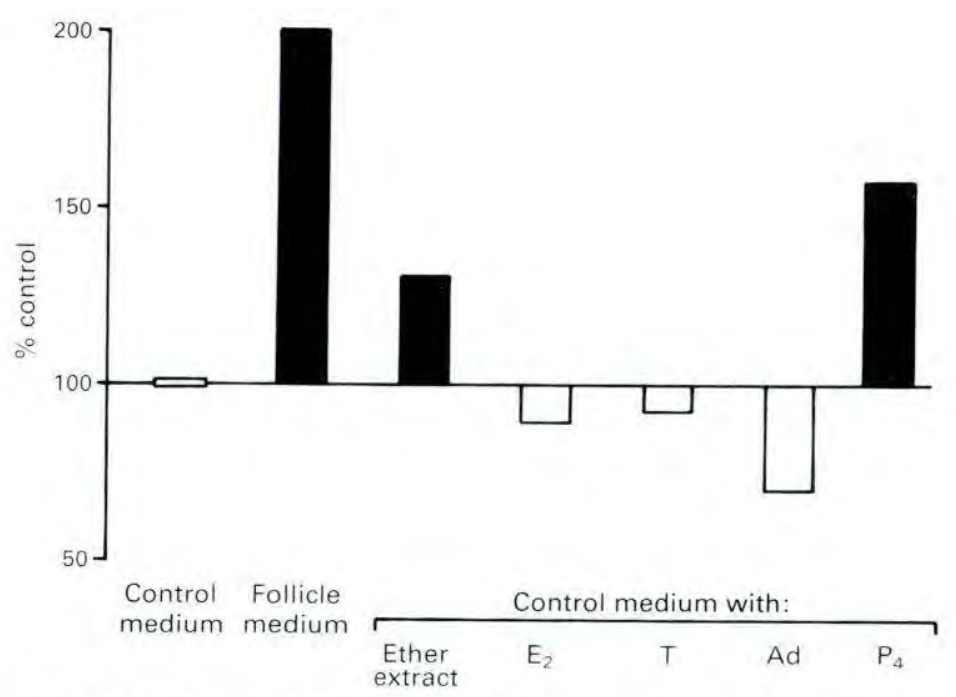

Fig. 7. Effect of follicle cell-conditioned medium and steroid supplementation on intercellular coupling in pig oocytes matured in vitro for $24 \mathrm{~h}$. The extent of intercellular coupling between oocytes and follicle cells cultured in control unsupplemented medium is expressed as $100 \%$ and the effect of supplementation is expressed relative to the controls (adapted from Mattioli et al., 1988b). $\mathrm{E}_{2}=$ oestradiol-17 $\beta ; \mathrm{T}=$ testosterone; $\mathrm{Ad}=$ androstenedione; $\mathrm{P}_{4}=$ progesterone.

\section{Conclusions}

Studies on pig oocyte development highlight, above all, the dominant role of follicle cells as regulators of growth, meiotic arrest and maturation. Although some steroid signals have already been identified other somatic regulators of oocyte function await identification. Similarly, intercellular communication between the follicle cells and oocyte is of evident importance at most stages of oocyte development. However, much remains to be discovered about the relative importance of 
intercellular communication for nutrient uptake on the one hand and signal transduction on the other. There is inadequate information on the intracellular molecular events involved in the sequestering of products during growth and their time-dependent redistribution and utilization at maturation, fertilization and during early embryonic development.

Sufficient information is, however, available for the development of in-vitro methods for oocyte maturation. It is clear that full maturation can be induced provided only that sufficient follicle cell support is available and that the junctional communication between the somatic and germinal compartments remain functional for the first $32 \mathrm{~h}$ of culture. Gonadotrophic hormones are required for pig oocyte maturation and a non-static culture system appears to ensure a more normal differentiation pattern than that achieved with current static culture methods. The requirements for normal in-vitro maturation outlined above have been achieved in a number of laboratories and have yielded normal embryos and healthy viable piglets (Mattioli et al., 1989).

We thank Dr Giovanna Lazzari for permission to refer to her unpublished work; and Mrs Linda Notton and Mrs Dianne Styles for preparing the typescript.

\section{References}

Ainsworth, L., Tsang, B.K., Downey, B.R., Marcus, G.J. \& Armstrong, D.T. (1980) Interrelationships between follicular fluid steroid levels, gonadotrophic stimuli, and oocyte maturation during preovulatory development of porcine follicles. Biol. Reprod. 23, $621-627$.

Bachvarova, R., Baran, M.M. \& Tejblum, A. (1980) Development of naked growing mouse oocytes in vitro. J. exp. Zool. 211, 159-169.

Bachvarova, R., De Leon, V., Johnson, A., Kaplan, G. \& Paynton, B.V. (1985) Changes in total RNA, polyadenylated RNA, actin mRNA during meiotic maturation of mouse oocytes. Devl Biol. 108, 325-331.

Buccione, R., Cecconi, S., Tatone, C., Mangia, F. \& Colonna, R. (1987) Follicle cell regulation of mammalian oocyte growth. J. exp. Zool. 242, 351-354.

Cran, D.G. \& Cheng, W.T.K. (1986) The cortical reaction of pig oocytes during in vivo and in vitro fertilization. Gamete Res. 13, 241-251.

Daguet, M.C. (1980) In vivo change in the germinal vesicle of the sow oocyte during the follicular phase before the ovulatory LH surge. Reprod. Nutr. Develop. 20, 673-680.

Dekel, N. \& Beers, W.H. (1978) Rat oocyte maturation in vitro: relief of cAMP inhibition by gonadotrophins. Proc. natn. Acad. Sci., U.S.A. 75, $4369-4373$.

Draetta, G., Luca, F., Westendorf, J., Brizuela, L., Ruderman, J. \& Beach, D. (1989) cdc2 Protein kinase is complexed with both cyclin A and B: evidence for proteolytic inactivation of MPF. Cell 56, 829-838.

Dunphy, W.G. \& Newport, J.W. (1988) Unravelling of meiotic control mechanisms. Cell 55, 925-928.

Eppig, J. (1977) Mouse development in vitro with various culture systems. Devl Biol. 60, 371-388.

Eppig, J.J. (1979) A comparison between oocyte growth in co-culture with granulosa cells and oocytes with granulosa cell-oocyte junctional contact maintained in vitro. J. exp. Zool. 209, 345-353.
Fleming, A.D., Kuehl, T.J. \& Armstrong, D.T. (1985) Maturation of pig and rat oocytes transplanted into surrogate pig follicles in vitro. Gamete Res. 11, 107-109.

Foote, W.D. \& Thibault, C. (1969) Recherches experimentales sur la maturation in vitro des ovocytes de truie et de veau. Annls Biol. anim. Biochim. Biophys. 9, 329-349.

Fulka, J., Jr, Motlík, J., Fulka, J. \& Crozet, N. (1985) Inhibition of nuclear maturation in fully grown porcine and mouse oocytes after their fusion with growing porcine oocytes. J. exp. Zool. 235, 255-259.

Fulka, J., Jr, Motlík, J., Fulka, J. \& Crozet, N. (1986a) Activity of maturation promoting factor in mammalian oocytes after its dilution by single and multiple fusions. Devl Biol. 118, 176-181.

Fulka, J., Jr, Motlík, J., Fulka, J. \& Jilek, F. (1986b) Effect of cycloheximide on nuclear maturation of pig and mouse oocytes. J. Reprod. Fert. 77, 281-285.

Fulka, J., Jr, Fléchon, J.E., Motlík, J. \& Fulka, J. (1988) Does autocatalytic amplification of maturation promoting factor (MPF) exist in mammalian oocytes? Gamete Res. 21, 185-192.

Gosden, R.G. \& Telfer, E. (1987) Numbers of follicles and oocytes in mammalian ovaries and their allometric relationships. J. Zool., Lond. 211, 169-175.

Greenwald, G.S. \& Moor, R.M. (1989) Isolation and preliminary characterization of pig primordial follicles. J. Reprod. Fert. 87, 561-571.

Herlands, A.L. \& Schultz, R.M. (1984) Regulation of mouse oocyte growth: Probable nutritional role for intercellular communication between follicle cells and oocytes in oocyte growth. J. exp. Zool. 229, $317-325$.

Hunter, A.G. \& Moor, R.M. (1987) Stage dependent effects of inhibiting RNA and protein synthesis on meiotic maturation of bovine oocytes in vitro. $J$. Dairy Sci. 70, 1646-1651.

Hunter, R.H.F. (1972) Fertilization in the pig: sequence of nuclear and cytoplasmic events. J. Reprod. Fert. 29, $395-406$. 
Iritani, A., Niwa, K. \& Imai, H. (1978) Sperm penetration in vitro of pig follicular oocytes matured in culture. $J$. Reprod. Fert. 54, 379-383.

Iwamatsu, T. \& Chang, M.C. (1972) Sperm penetration in vitro of mouse oocytes at various times during maturation. J. Reprod. Fert. 31, 237-247.

Kubelka, M., Motlík, J., Fulka, J., Prochazka, R., Rimkevicova, Z. \& Fulka, J. (1988) Time sequence of germinal vesicle breakdown in pig oocytes after cycloheximide and P-amino-benzamidine block. Gamete Res. 19, 423-431.

Lee, M. \& Nurse, P. (1987) Complementation used to clone a human homologue of the fission yeast cell cycle control gene cde2. Nature, Lond. 327, 31-35.

Lokha, M.J. (1989) Mitotic control by metaphasepromoting factor and cdc2 proteins. J. Cell Sci. 92, 131-135.

Masui, Y. \& Markert, C. (1971) Cytoplasmic control of nuclear behaviour during meiotic maturation of frog oocytes. J. exp. Zool. 177, 129-146.

Mattioli, M. (1990) The role of follicular cells in maturation, fertilizability and developmental competence of pig oocytes. In In Vitro Approaches to Mammalian Gamete Maturation and Embryonic Development (in press). Ed. A. Lauria. Serover Press, Rome.

Mattioli, M., Galeati, G. \& Seren, E. (1988a) Effect of follicle somatic cells during pig oocyte maturation on egg penetrability and male pronucleus formation. Gamete Res. 20, 177-183.

Mattioli, M., Galeati, G., Bacci, M.L. \& Seren, E. (1988b) Follicular factors influence oocyte fertilizability by modulating the intercellular co-operation between cumulus cells and oocytes. Gamete Res. 21, 223-232.

Mattioli, M., Bacci, M.L., Galeati, G. \& Seren, E. (1989) Developmental competence of pig oocytes matured and fertilized in vitro. Theriogenology 31, 1201-1207.

McGaughey, R.W., Montgomery, D.H. \& Richter, J.D. (1979) Germinal vesicle configurations and patterns of polypeptide synthesis of porcine oocytes from antral follicles of different size, as related to their competency for spontaneous maturation. J. exp. Zool. 209, 239-254.

Meinecke, B. \& Meinecke-Tillman, S. (1981) Induction and inhibition of meiotic maturation of follicleenclosed porcine oocytes in vitro. Theriogenology $\mathbf{1 5}$, 581-589.

Moor, R.M. (1983) Contact signalling and co-operation between follicle cells and dictyate oocytes in mam- mals. In Current Problems in Germ Cell Differentiation in Mammals, pp. 307-326. Eds A. McLaren \& C. C. Wylie. Cambridge University Press, Cambridge.

Moor, R.M. \& Crosby, I.M. (1986) Protein requirements for germinal vesicle breakdown in ovine oocytes. $J$. Embryol. exp. Morph. 94, 207-220.

Moor, R.M. \& Crosby, I.M. (1987) Cellular origin, hormonal regulation and biochemical characteristics of polypeptides secreted by Graafian follicles of sheep. J. Reprod. Fert. 79, 469483.

Moor, R.M. \& Powell, D. (1989) Translational capacity of sheep oocytes microinjected with messenger RNA. J. Reprod. Fert. 86, $289-295$.

Moor, R.M. \& Seamark, R.F. (1986) Cell signalling, permeability and microvasculatory changes during antral follicle development in mammals, J. Dairy Sci. 69, 927-943.

Motlík, J. \& Fulka, J. (1976) Breakdown of the germinal vesicle in pig oocytes in vivo and in vitro. J. exp. Zool. 198, $155-162$.

Motlík, J. \& Fulka, J. (1986) Factors affecting meiotic competence in pig oocytes. Theriogenology 25, 87-97.

Motlík, J., Crozet, N. \& Fulka, J. (1984a) Meiotic competence in vitro of pig oocytes isolated from early antral follicles. J. Reprod. Fert. 72, 323-328.

Motlík, J., Kopecny, V., Travník, P. \& Pivko, J. (1984b) RNA synthesis in pig follicular oocytes. Autoradiographic and cytochemical study. Biol. Cell 50, 229-236.

Motlík, J., Fulka, J. \& Fléchon, J-E. (1986) Changes in intercellular coupling between pig oocytes and cumulus cells during maturation in vivo and in vitro. $J$. Reprod. Fert. 76, 31-37.

Racowsky, C. (1985) Effect of forskolin on meiotic arrest and stimulation of cumulus expansion, progesterone and cyclic AMP production by pig cumulus-oocyte complexes. J. Reprod. Fert. 74, 9-21.

Thibault, C. (1977) Are follicular maturation and oocyte maturation independent progresses? J. Reprod. Fert. 51, 1-15.

Thibault, C., Gerard, M. \& Menezo, Y. (1975) Acquisition par l'oocyte de lapine et de veau du faceur de decondensation du noyau du spermatozoide fecondant (MPGF). Annls Biol. anim. Biochim. Biophys. 15, 705-714.

Thibault, C., Szollosi, D. \& Gerard, M. (1987) Mammalian oocyte maturation. Reprod. Nutr. Develop. 27, 856-896. 